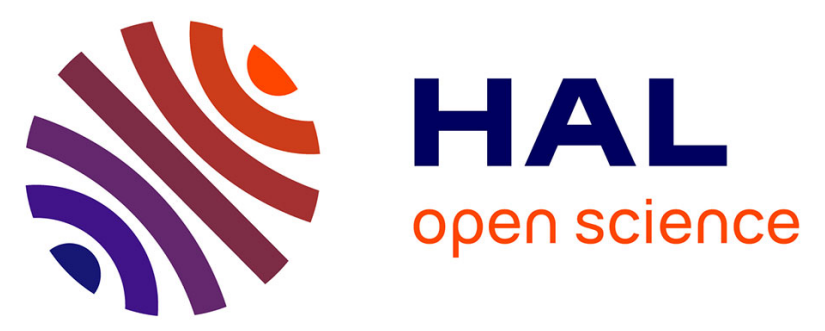

\title{
Optimization of extended basis sets and assessment of different theoretical schemes for $\mathrm{Pb}$ containing compounds
}

Jean-Yves Salpin, Jeanine Tortajada, Manuel Alcamí, Otilia Mó, Manuel Yáñez

\section{To cite this version:}

Jean-Yves Salpin, Jeanine Tortajada, Manuel Alcamí, Otilia Mó, Manuel Yáñez. Optimization of extended basis sets and assessment of different theoretical schemes for $\mathrm{Pb}$ containing compounds. Chemical Physics Letters, 2004, 383 (5-6), pp.561-565. 10.1016/j.cplett.2003.11.073 . hal-00068617

\section{HAL Id: hal-00068617 https://hal.science/hal-00068617}

Submitted on 5 Oct 2018

HAL is a multi-disciplinary open access archive for the deposit and dissemination of scientific research documents, whether they are published or not. The documents may come from teaching and research institutions in France or abroad, or from public or private research centers.
L'archive ouverte pluridisciplinaire HAL, est destinée au dépôt et à la diffusion de documents scientifiques de niveau recherche, publiés ou non, émanant des établissements d'enseignement et de recherche français ou étrangers, des laboratoires publics ou privés. 
Optimization of extended basis sets and assessment of different theoretical schemes for $\mathrm{Pb}$ containing compounds.

\title{
J.-Y. Salpin and J. Tortajada
}

Laboratoire Analyse et Environnement, UMR CNRS 8587, Université d'Evry Val d’Essonne. Institut des Sciences, Boulevard François Mitterrand, 91025 EVRY CEDEX, France.

\section{Alcamí, O. Mó and M. Yáñez}

Departamento de Química, C-9. Universidad Autónoma de Madrid. Cantoblanco. 28049-Madrid. Spain

\begin{abstract}
Extended basis sets for $\mathrm{Pb}$ to be used in conjunction with the SKBJ and the Stuttgart effective core potentials (ECPs) have been optimized. An assessment of different ab initio and density functional procedures showed that all methods based on the use of the SKBJ ECP exaggerate the $\mathrm{Pb}^{+}$binding enthalpies, which are systematically $35-50 \mathrm{~kJ} \mathrm{~mol}^{-1}$ larger than those obtained when the Stuttgart ECP is employed. The G96LYP/Stutt method yields values in close agreement with those obtained at the QCISD(T)/Stutt and $\operatorname{CCSD}(\mathrm{T}) /$ Stutt levels of theory, but at a significantly lower cost. Also the B3LYP/Stutt, the BLYP/Stutt and the MP2/Stutt approaches provide a good compromise between accuracy and computational cost for the calculation of binding enthalpies.
\end{abstract}




\section{Introduction}

The study of the reactivity of transition metal ions attracted much attention in the last two decades[1,2] because they are involved in many chemical and biochemical processes. A large number of these transition metals are highly toxic, and this toxicity is normally related to the reactivity of their cationic forms. Lead is an archetype example that produces damages to mammals health. It perturbs the heme biosynthesis, interacts with nucleic acids, crosses the placenta and affects protein synthesis[3], and is a largely spread pollutant. [4] All this motivated a growing interest in the comprehension of the factors governing the reactivity of $\mathrm{Pb}^{+}$and $\mathrm{Pb}^{2+}$, that frequently exhibit a specific reactivity. [5,6]

A good knowledge of the reactivity patterns of metal ions requires an accurate description of the topology of the corresponding potential energy surface (PES). This description is normally attained through the use of ab initio or density functional theory (DFT) calculations. If a reliable description of reactants, products and reaction intermediates is needed one is compelled to use the so-called high-level ab initio or DFT calculations, that require flexible enough basis sets, which are not always available, in particular when dealing with atoms of the third or fourth row[7-9].

The aim of this paper is to provide extended basis sets for lead to be used in conjunction with the typical basis set expansions employed in high-level ab initio approaches, such as the G2 theory[10]. The second part of this article will be devoted to the assessment of the optimized basis expansions when used with different ab initio and DFT methods. 


\section{Computational Details}

Different effective core potentials have been proposed in the literature for $\mathrm{Pb}$. In our study we have considered two of them: the Stuttgart relativistic pseudopotential[11] and the SKBJ pseudo-potential of Stevens et al[12]. These two ECP approaches use different basis sets to describe the valence electrons for third and fourthrow atoms. The SKBJ method employs a $(5 s, 5 p) /[2 s, 2 p]$ basis set which implies a $[4,1]$ contraction scheme; the Stuttgart ECP uses a smaller $(4 s, 4 p) /[2 s, 2 p]$ basis with a $[3,1]$ contraction scheme. On the other hand in the SKBJ approach a typical shell-structure $\left(\alpha_{s}=\alpha_{p}\right)$ is adopted while this approximation is not used in the Sttutgart method, which in contrast includes a set of $d$ polarization functions, which is not included in the SKBJ ECP.

In most of the so-called high-level methods, geometry optimizations are carried out at MP2/6-31G(d) or B3LYP/6-31G(d) level of theory. The Sttutgart ECP contains $d$ polarization functions, and therefore the corresponding $(4 s, 4 p, 1 d) /[2 s, 2 p, 1 d]$ basis set can be directly used for the geometry optimizations without further refinement. For the SKBJ pseudo-potential, the optimization of the $d$ polarization function must be carried out. The exponent of this polarization function was optimized for $\mathrm{PbH}_{4}$, on its experimental geometry[13] at the MP2 level. The value so obtained is shown in Table 1.

Hereafter, the basis set developed for $\mathrm{Pb}$ to be used in conjunction with 631G(d), 6-311G(d), and 6-311+G(3df,2p) basis for the remaining atoms will be also referred to as $6-31 G(d), 6-311 G(d)$ and $6-311+G(3 d f, 2 p)$ basis sets, for the sake simplicity.

To obtain the supplementary diffuse $s, p$ components and the $d, f$ polarization functions required to built a G2-type 6-311+G(3df,2p) basis set, we have followed similar procedures to those described in the literature[7,8]. To generate a triple-zeta 
quality (6-311G-type) basis set, we have partially uncontracted the original valence basis sets of the Stuttgart scheme, by replacing the $[3,1]$ contraction by a $[2,1,1]$ one, whereas in the particular case of the SKBJ ECP, we have completely uncontracted the original $[4,1]$ scheme, following the suggestion of refs. [7,8].

Optimization of the $3 d$ functions to build $6-311+G(3 d f, 2 p)$-type basis

Using the aforementioned contraction schemes for $\mathrm{Pb}$ and a 311G(p) basis set for hydrogen, the exponent of the $d$ polarization function was optimized through QCISD(T) calculations for $\mathrm{PbH}_{4}$. To create multiple sets of $d$ functions from a single optimized function we have adopted the usual procedure, in which the new exponents are obtained as multiples, n $\alpha_{\mathrm{d}}$, or fractions, $\alpha_{\mathrm{d}} / \mathrm{n}$, of the single optimized exponent $\alpha_{\mathrm{d}}$. The best results are obtained for $\mathrm{n}=1.5$ for the $(2 d)$ splitting and $\mathrm{n}=2$ for the $(3 d)$ splitting, which coincide with the values normally used for fourth-row elements[7]. Optimization of the fand the set of sp diffuse functions

With the 6-311G(d,p) basis generated in the previous step a set of diffuse $s, p$ functions (with the constraint $\alpha_{s}=\alpha_{p}$ in the case of SKBJ potential), was optimized at the QCISD(T) level of theory for the $\mathrm{PbH}_{3}{ }^{-}$species, on its LANL2 optimized geometry. The set of $f$ polarization functions was then obtained through QCISD(T)/6-311G(2df, p) calculations for $\mathrm{PbH}_{4}$. The values of the different exponents so optimized are given in Table 1.

With the two sets of extended basis set optimized as indicated above the assessment of different ab initio methods including MP2, QCISD(T) and CCSD(T) and several density functionals, namely BLYP, B3LYP, G96LYP, B3PW91, MPW1PW91, PBEPBE and PBE1PBE, which include hybrid and non-hybrid approaches was carried out, by comparing calculated and experimental binding enthalpies, vibrational frequencies and geometries. Unfortunately, there is not much accurate experimental 
information regarding $\mathrm{Pb}$ containing systems. We are only aware of the existence of measured binding enthalpies [1]for the following complexes: $\mathrm{H}_{2} \mathrm{O}-\mathrm{Pb}^{+}, \mathrm{NH}_{3}-\mathrm{Pb}^{+}$, $\mathrm{CH}_{3} \mathrm{OH}-\mathrm{Pb}^{+}$and $\mathrm{CH}_{3} \mathrm{NH}_{2}-\mathrm{Pb}^{+}$, that will be used in our assessment.

\section{Results and discussion}

\section{Geometries}

For the best of our knowledge only for $\mathrm{PbH}_{4}$ an extrapolated value for the $\mathrm{PbH}$ bond length have been reported in the literature [13]so far. The optimized values using the MP2 method and different functionals are summarized in Table 2. In general, the agreement between calculated and "experimental" values is always reasonably good, although the Stuttgart ECP yields bond length slightly short.

\section{Vibrational Frequencies}

We have found experimental vibrational frequencies only for the $\Sigma_{\mathrm{g}}{ }^{+}$and the $\Sigma_{\mathrm{u}}{ }^{+}$ vibrational bands $\mathrm{PbO}_{2}$. [14] In Table 3 we compare the experimental values with those predicted by different theoretical schemes. As it could be anticipated the MP2 values overestimate the experimental ones. However, the agreement is very good if the MP2 values are scaled by the empirical factor 0.9427 proposed in the literature[15]. Conversely, and with the only exception of the B3LYP/SKBJ method, the DFT values slightly underestimate the experimental ones. The best agreement is obtained at the G96LYP/SKBJ method, but as we shall discuss in forthcoming sections, this approach performs quite poorly as far as $\mathrm{Pb}^{+}$binding enthalpies are concerned.

\section{$\mathrm{Pb}^{+}$binding enthalpies}

The $\mathrm{Pb}^{+}$binding enthalpy of a ligand $\mathrm{L}$ is given by the enthalpy of reaction (1)

$$
\mathrm{Pb}^{+}+\mathrm{L} \stackrel{\Delta \mathrm{H}^{\circ}}{\longrightarrow} \mathrm{Pb}(\mathrm{L})^{+}
$$

The calculated values include systematically the corresponding counterpoise BSSE correction. 
In the nomenclature adopted hereafter, the name of the theoretical scheme, for example $\operatorname{CCSD}(\mathrm{T}) /$ Stutt implies that the $\operatorname{CCSD}(\mathrm{T})$ procedure using the Stuttgart ECP was used together with a $6-311+G(2 d f, 2 p)$ basis set. The single-point ab initio calculations are carried out, unless otherwise stated, on MP2/6-31G(d,p) optimized geometries. DFT calculations are performed on geometries optimized using the same functional and a 6-31G(d,p) basis set. Hence, for instance, QCISD(T)/Stutt and B3LYP/SKBJ stand for QCISD(T)/6-311+G(2df,2p)//MP2/6-31G(d,p) calculations using the Stuttgart ECP and B3LYP/6-311+G(2df,2p)//B3LYP/6-31G(d,p) calculations using the SKBJ ECP, respectively.

Effect of the third set of d polarization functions

In previous studies involving transition metal cations it was claimed [16]that the role of the third set of $d$ polarization functions in a $6-311+G(3 \mathrm{df}, 2 \mathrm{p})$ expansion has a negligible small effect on calculated binding enthalpies, so that the use of a 6$311+G(2 d f, 2 p)$ basis set leads to very similar values but at a lower cost. Hence, this was the first point we decided to address in our analysis of the performance of our optimized basis set. The values obtained when different ab initio and DFT approaches are used are shown in Table 4. The effect of the third set of $d$ polarization functions for DFT methods is much smaller than for ab initio approaches. This is not surprising because in general DFT methods are less sensitive to changes in the basis set expansion. As a matter of fact, the effects of the third $d$ basis set is negligible small when DFT methods are used being particularly small for the SKBJ ECP. For QCI and CC methods the inclusion of the third set of $d$ functions leads to changes in the binding energy never larger than $4 \mathrm{~kJ} / \mathrm{mol}$. 
Influence of the geometry.

We have considered also of interest to investigate the influence of the level used for the geometry optimization on the final value of the $\mathrm{Pb}^{+}$binding enthalpies when obtained in single-point high-level QCISD(T) or $\operatorname{CCSD}(\mathrm{T})$ ab initio calculations. In Table 5 we compare the $\mathrm{Pb}^{+}$binding enthalpies obtained when different optimized geometries are used. It can be observed that the optimized geometry used can account for binding enthalpy differences of about 3-4 kJ/mol. Systematically the calculated binding enthalpies based on DFT optimized structures are smaller than those based on MP2 optimized geometries, and in better agreement with the experimental values. This is consistent with previous findings reported in the literature[17] which showed that the use of DFT rather than MP2 optimized geometries, usually improves the accuracy of methods such as G2 or G3[18]. The effect of the functional used in the geometry optimization is not significantly large, but the values obtained using B3LYP optimized geometries are, in general, closer to the experimental values than those obtained using G96LYP optimized geometries.

Performance of the different ECPs

A comparison of the values reported in Tables 4 and 5, clearly shows that all methods, either ab initio or DFT based on the SKBJ ECP yield $\mathrm{Pb}^{+}$binding enthalpies from 35 to $50 \mathrm{~kJ} \mathrm{~mol}^{-1}$ larger than those obtained when the Stuttgart ECP is employed, and in much worse agreement with the experimental values. It is interesting to note that this effect is quantitatively very similar for ab initio and DFT methods. It must be also mention that a completely similar behavior was found when other functionals, namely BLYP, B3PW91, MPW1PW91, PBEPBE and PBE1PBE, were used (see Table 6). 


\section{Performance of the different functionals}

Table 6 shows that if the Stuttgart ECP is used, the G96LYP approach yields the best $\mathrm{Pb}^{+}$binding enthalpies. Rather similar, although slightly greater, are the estimates obtained by the B3LYP/Stutt and the BLYP/Stutt methods, that yield very similar values for all ligands investigated.

It is also worthwhile to compare the DFT calculated values with those obtained at high ab initio levels. Firstly, it must be noted, as shown in Table 5, that QCISD(T)/Stutt and CCSD(T)/Stutt methods yield quite similar binding enthalpies. Also importantly, the G96LYP/Stutt calculated values are very close to those obtained at the QCISD(T)/Stutt(B3LYP) and CCSD(T)/Stutt(B3LYP) levels of theory, but at a much lower computational cost. Also interestingly, the $\mathrm{Pb}^{+}$binding enthalpies obtained at the much cheaper MP2/Stutt level are only 3-5 $\mathrm{kJ} \mathrm{mol}^{-1}$ higher than the QCISD(T)/Stutt(B3LYP) and CCSD(T)/Stutt(B3LYP) estimates.

\section{Conclusions}

We have shown that the 6-31G(d,p) basis sets optimized to be used either with the SKBJ or the Stuttgart ECPs, yield reasonably good geometries and vibrational frequencies, almost independently of the method used, although the best vibrational frequencies seem to be those obtained when the G96LYP/SKBJ approach is employed.

Very different is the situation as far as the $\mathrm{Pb}^{+}$binding enthalpies are concerned. All methods based on the use of the SKBJ ECP exaggerate dramatically these binding enthalpies, which are systematically $35-50 \mathrm{~kJ} \mathrm{~mol}^{-1}$ larger than those obtained when the Stuttgart ECP is employed. We have also shown that the inclusion of a third set of $d$ polarization functions have an almost negligible small effect on the calculated binding enthalpies, so that for the sake of economy the use of a $6-311+G(2 d f, 2 p)$ basis set expansion is recommended. 
It seems advisable the use of DFT rather than MP2 optimized geometries for single-point high-level ab initio calculations.

The G96LYP/Stutt method yields binding enthalpies in close agreement with those obtained at the QCISD(T)/Stutt and $\operatorname{CCSD}(\mathrm{T}) /$ Stutt levels of theory, but at a significantly lower cost. Also the B3LYP/Stutt, the BLYP/Stutt and the MP2/Stutt approaches provide a good compromise between accuracy and computational cost in the calculation of binding enthalpies.

Acknowledgement. This work has been partially supported by the DGI Project No. BQU2000-0245, by the COST Action D26/0014/03 and by the Acción Integrada Hispano-Francesa HF2001-0042. JYS and JT would like to thank the Institut du Développement et des Ressources en Informatique Scientifique (IDRIS, CNRS) for computational time

\section{References}

[1] B.S. Freiser: Organometallic Ion Chemistry, Kluwer Academic Publishers, Dordrecht, 1995.

[2] A. Sigel, H. Sigel: Metal ions in biological systems, Marcel Dekker, New York, 1996.

[3] O.C. Uhlenbeck, T. Pan, Nature 358 (1992) 560.

[4] R.D. Rhue, R.S. Mansell, L.T. Ou, R. Cox, S.R. Tang, Y. Ouyang, Cirt. Rev. Environ. Control 22 (1992) 169.

[5] J.-Y. Salpin, J. Tortajada, L. Boutreau, V. Hadys, Eur. J. Mass Spectrom. 7 (2001) 321.

[6] J.-Y. Salpin, J. Tortajada, Adv. Mass Spectrom. 15 (2001) 735.

[7] M.N. Glukhovtsev, A. Pross, M.P. McGrath, L. Radom, J. Chem. Phys. 103 (1995) 1878. 
[8] A.I. González, O. Mó, M. Yáñez, J. Chem. Phys. 112 (2000) 2258.

[9] J.M. Mercero, X. López, J.E. Fowler, J.M. Ugalde, J. Phys. Chem. A 101 (1997) 5574.

[10] L.A. Curtiss, K. Raghavachari, G.W. Trucks, J.A. Pople, J. Chem. Phys. 94 (1991) 7221.

[11] W. Kuechle, M. Dolg, H. Stoll, H. Preuss, Mol. Phys. 74 (1991) 1245.

[12] W.J. Stevens, M. Krauss, H. Basch, P.G. Jasien, Can. J. Chem. 70 (1992) 612.

[13] J.P. Desclaux, P. Pyykkö, Chem. Phys. Lett. 29 (1974) 534.

[14] G.V. Chertihin, J. Andrews, J. Chem. Phys. 105 (1996) 2561.

[15] M.J. Frisch, J.B. Foresman: Exploring Chemistry with electronic structure methods, Gassian, Inc., Pittsburgh, 1996.

[16] A. Luna, B. Amekraz, J. Tortajada, Chem. Phys. Lett. 266 (1997) 31.

[17] M. Alcamí, O. Mo, M. Yanez, Mass Spectrom. Rev. 20 (2001) 195.

[18] L.A. Curtiss, P.C. Redfern, K. Raghavachari, J.A. Pople, J. Chem. Phys. 114 (2001) 108. 
Table 1. Optimized exponents for polarization and diffuse functions for $\mathrm{Pb}$ to be used with two different ECPs

\begin{tabular}{|l|c|c|}
\hline Exponent & STUTTGART & SKBJ \\
\hline$\alpha_{d}$ (geometry optimization) & $0.1700^{\mathrm{a}}$ & 0.1766 \\
\hline$\alpha_{d}$ (single point) & 0.1950 & 0.2072 \\
\hline$\alpha_{f}$ & 0.3752 & 0.3021 \\
\hline$\alpha_{s p}$ (diffuse) & - & $0.0872^{\mathrm{b}}$ \\
\hline$\alpha_{s}$ (diffuse) & $0.0326^{\mathrm{c}}$ & \\
\cline { 1 - 2 }$\alpha_{p}$ (diffuse) & $0.0292^{\mathrm{c}}$ & \\
\cline { 1 - 2 } & &
\end{tabular}

a This exponent is already included in the standard basis set of this ECP

${ }^{\mathrm{b}}$ Exponents optimized with the restriction $\alpha_{\mathrm{s}}=\alpha_{p}$

${ }^{\mathrm{c}}$ Exponents optimized without the restriction $\alpha_{s}=\alpha_{p}$

Table 2. Optimized bond lengths ( $\mathrm{R}$, in $\AA$ ) for $\mathrm{PbH}_{4}$

\begin{tabular}{|l|c|}
\hline Method & $\mathrm{R}$ \\
\hline MP2/Stutt & 1.740 \\
\hline MP2/SKBJ & 1.751 \\
\hline B3LYP/Stutt & 1.738 \\
\hline B3LYP/SKBJ & 1.748 \\
\hline G96LYP/Stutt & 1.746 \\
\hline G96LYP/SKBJ & 1.758 \\
\hline BLYP/Stutt & 1.745 \\
\hline BLYP/SKBJ & 1.758 \\
\hline Experimental & 1.754 \\
\hline
\end{tabular}

Table 3. Vibrational frequencies ${ }^{\mathrm{a}}$ ( in $\mathrm{cm}^{-1}$ ) of $\mathrm{PbO}_{2}$

\begin{tabular}{|l|l|l|}
\hline Method & $\sum_{\mathrm{g}}{ }^{+}$band & $\sum_{\mathrm{u}}{ }^{+}$band \\
\hline MP2/SKBJ & $752(709)$ & $929(876)$ \\
\hline MP2/Stutt & $720(679)$ & $896(845)$ \\
\hline B3LYP/SKBJ & 678 & 776 \\
\hline B3LYP/Stutt & 650 & 711 \\
\hline G96LYP/SKBJ & 656 & 763 \\
\hline G96LYP/Stutt & 624 & 693 \\
\hline BLYP/SKBJ & 653 & 757 \\
\hline BLYP/Stutt & 622 & 691 \\
\hline Experiment & 658.6 & 764.8 \\
\hline
\end{tabular}

a Values within parenthesis have been scaled by the empirical factor 0.9427 
Table 4. Influence of the third set of $d$ polarization functions on calculated $\mathrm{Pb}^{+}$binding enthalpies $\left(\Delta \mathrm{H}^{\circ}, \mathrm{kJ} / \mathrm{mol}\right)$ using different theoretical schemes.

\begin{tabular}{|c|c|c|c|c|}
\hline & \multicolumn{4}{|c|}{$\Delta \mathrm{H}^{\circ}$} \\
\hline Method & $\mathrm{H}_{2} \mathrm{O}$ & $\mathrm{NH}_{3}$ & $\mathrm{CH}_{3} \mathrm{OH}$ & $\mathrm{CH}_{3} \mathrm{NH}_{2}$ \\
\hline QCISD(T)/Stutt & -103.9 & -145.0 & -123.2 & -158.7 \\
\hline QCISD(T)/Stutt_3df ${ }^{a}$ & -105.0 & -145.4 & -124.6 & -159.8 \\
\hline QCISD(T)/SKBJ & -144.2 & -181.2 & -168.8 & -203.9 \\
\hline QCISD(T)/SKBJ_3df ${ }^{\mathrm{a}}$ & -140.1 & -176.4 & -165.1 & -199.7 \\
\hline CCSD(T)/Stutt & -103.1 & -144.9 & -123.4 & -158.6 \\
\hline CCSD(T)/Stutt_3df ${ }^{a}$ & -105.0 & -145.4 & -124.4 & -159.7 \\
\hline CCSD(T)/SKBJ & -144.1 & -181.1 & -168.6 & -203.9 \\
\hline CCSD(T)/SKBJ_3df & -145.1 & -181.6 & -169.9 & -204.8 \\
\hline B3LYP/Stutt & -107.7 & -143.6 & -125.9 & -157.4 \\
\hline B3LYP/Stutt_3df ${ }^{a}$ & -107.2 & -143.3 & -126.0 & -158.3 \\
\hline B3LYP/SKBJ & -149.3 & -181.6 & -171.9 & -200.6 \\
\hline B3LYP/SKBJ_3df ${ }^{\mathrm{a}}$ & -149.1 & -181.6 & -172.1 & -201.2 \\
\hline G96LYP/Stutt & -99.7 & -139.2 & -118.4 & -153.9 \\
\hline G96LYP/Stutt_3df ${ }^{a}$ & -99.8 & -139.4 & -119.0 & -152.9 \\
\hline G96LYP/SKBJ & -141.0 & -176.6 & -164.1 & -197.3 \\
\hline G96LYP/SKBJ_3df ${ }^{a}$ & -140.6 & -176.5 & -164.3 & -197.8 \\
\hline
\end{tabular}

${ }^{\text {a }}$ Calculations carried out using a 6-311+G(3df,2p) basis set. 
Table 5. Effect of the optimized geometry on the calculated $\mathrm{Pb}^{+}$binding enthalpies $\left(\Delta \mathrm{H}^{\circ}, \mathrm{kJ} \mathrm{mol}^{-1}\right)$.

\begin{tabular}{|c|c|c|c|c|}
\hline & \multicolumn{4}{|c|}{$\Delta \mathrm{H}^{\circ}$} \\
\hline Method & $\mathrm{H}_{2} \mathrm{O}$ & $\mathrm{NH}_{3}$ & $\mathrm{CH}_{3} \mathrm{OH}$ & $\mathrm{CH}_{3} \mathrm{NH}_{2}$ \\
\hline MP2/Stutt & -104.9 & -145.4 & -125.2 & -160.5 \\
\hline MP2/SKBJ & -133.1 & -169.7 & -158.2 & -193.2 \\
\hline QCISD(T)/Stutt & -103.9 & -145.0 & -123.2 & -158.7 \\
\hline QCISD(T)/Stutt(B3LYP) ${ }^{\mathrm{a}}$ & -100.3 & -140.0 & -122.5 & -156.8 \\
\hline QCISD(T)/Stutt(G96LYP) & -103.1 & -140.2 & -122.5 & -157.4 \\
\hline QCISD(T)/SKBJ & -144.2 & -181.2 & -168.8 & -203.9 \\
\hline QCISD(T)/SKBJ(B3LYP) ${ }^{\mathrm{a}}$ & -140.9 & -177.1 & -168.3 & -199.5 \\
\hline QCISD(T)/SKBJ(G96LYP) ${ }^{b}$ & -143.8 & -177.9 & -168.2 & -202.5 \\
\hline CCSD(T)/Stutt & -103.1 & -144.9 & -123.0 & -158.6 \\
\hline CCSD(T)/Stutt(B3LYP) ${ }^{a}$ & -100.3 & -139.9 & -122.3 & -156.7 \\
\hline CCSD(T)/Stutt(G96LYP) & -103.1 & -140.2 & -122.3 & -157.3 \\
\hline CCSD(T)/SKBJ & -144.1 & $-181,1$ & -168.6 & -203.9 \\
\hline CCSD(T)/Stutt(B3LYP) ${ }^{a}$ & -140.9 & -177.0 & -168.1 & -200.0 \\
\hline CCSD(T)/Stutt(G96LYP) & -143.7 & -177.9 & -168.0 & -202.4 \\
\hline Experimental & -93.7 & -118.41 & -97.5 & -148.11 \\
\hline
\end{tabular}

${ }^{\text {a }}$ Calculations based on B3LYP/6-31g(d,p) optimized geometries

${ }^{\mathrm{b}}$ Calculations based on G96LYP/6-31g(d,p) optimized geometries 
Table 6. $\mathrm{Pb}^{+}$binding enthalpies $\left(\Delta \mathrm{H}^{\circ}, \mathrm{kJ} \mathrm{mol}^{-1}\right)$ calculated using different functionals.

\begin{tabular}{|c|c|c|c|c|}
\hline \multirow{2}{*}{ Method } & \multicolumn{4}{|c|}{$\Delta \mathrm{H}^{\circ}$} \\
\hline B3LYP/Stutt & -107.7 & -143.6 & -125.9 & -157.4 \\
\hline B3LYP/SKBJ & -149.3 & -181.6 & -171.9 & -200.6 \\
\hline B3PW91/Stutt & -112.9 & -153.2 & -129.8 & -167.4 \\
\hline B3PW91/SKBJ & -152.3 & -188.5 & -173.7 & -212.2 \\
\hline G96LYP/Stutt & -99.7 & -139.2 & -118.4 & -153.9 \\
\hline G96LYP/SKBJ & -141.0 & -176.6 & -164.1 & -197.3 \\
\hline MPW1PW91/Stutt & -113.1 & -153.0 & -129.8 & -166.1 \\
\hline MPW1PW91/SKBJ & -155.4 & -192.3 & -176.8 & -215.2 \\
\hline PBEPBE/Stutt & -118.0 & -160.6 & -136.5 & -175.7 \\
\hline PBEPBE/SKBJ & -160.2 & -198.8 & -183.7 & -224.9 \\
\hline PBE1PBE/Stutt & -115.4 & -155.5 & -131.8 & -168.1 \\
\hline PBE1PBE/SKBJ & -157.7 & -193.3 & -178.8 & -217.8 \\
\hline BLYP/Stutt & -106.2 & -143.9 & -126.2 & -158.3 \\
\hline BLYP/SKBJ & -147.3 & -181.1 & -171.7 & -203.4 \\
\hline Experimental & $-\mathbf{9 3 . 7}$ & $-\mathbf{1 1 8 . 4 1}$ & $-\mathbf{9 7 . 5}$ & -148.11 \\
\hline
\end{tabular}


Table 1. Optimized exponents for polarization and diffuse functions for $\mathrm{Pb}$ to be used with two different ECPs

\begin{tabular}{|c|c|c|}
\hline Exponent & STUTTGART & SKBJ \\
\hline$\alpha_{d}$ (geometry optimization) & $0.1700^{\mathrm{a}}$ & 0.1766 \\
\hline$\alpha_{d}$ (single point) & 0.1950 & 0.2072 \\
\hline$\alpha_{f}$ & 0.3752 & 0.3021 \\
\hline$\alpha_{s p}$ (diffuse) & $0.0326^{\mathrm{b}}$ & $0.0872^{\mathrm{b}}$ \\
\hline$\alpha_{s}$ (diffuse) & $0.0326^{\mathrm{c}}$ & \\
\hline$\alpha_{p}$ (diffuse) & $0.0292^{\mathrm{c}}$ & \\
\hline
\end{tabular}

${ }^{\text {a }}$ This exponent is already included in the standard basis set of this ECP

${ }^{\mathrm{b}}$ Exponents optimized with the restriction $\alpha_{s}=\alpha_{p}$

${ }^{\mathrm{c}}$ Exponents optimized without the restriction $\alpha_{s}=\alpha_{p}$ 
Table 2. Optimized bond lengths ( $\mathrm{R}$, in $\AA$ ) for $\mathrm{PbH}_{4}$

\begin{tabular}{|l|c|}
\hline Method & $\mathrm{R}$ \\
\hline MP2/Stutt & 1.740 \\
\hline MP2/SKBJ & 1.751 \\
\hline B3LYP/Stutt & 1.738 \\
\hline B3LYP/SKBJ & 1.748 \\
\hline G96LYP/Stutt & 1.746 \\
\hline G96LYP/SKBJ & 1.758 \\
\hline BLYP/Stutt & 1.745 \\
\hline BLYP/SKBJ & 1.758 \\
\hline Experimental & 1.754 \\
\hline
\end{tabular}


Table 3. Vibrational frequencies ${ }^{\mathrm{a}}$ ( in $\mathrm{cm}^{-1}$ ) of $\mathrm{PbO}_{2}$

\begin{tabular}{|c|c|c|c|c|c|c|c|c|c|}
\hline Band & Experiment & MP2/SKBJ & MP2/Stutt & B3LYP/SKBJ & B3LYP/Stutt & G96LYP/SKBJ & G96LYP/Stutt & BLYP/SKBJ & BLYP/Stutt \\
\hline
\end{tabular}

${ }^{a}$ Values within parenthesis have been scaled by the empirical factor 0.9427 
Table 4. Influence of the third set of $d$ polarization functions on calculated $\mathrm{Pb}^{+}$binding enthalpies $\left(\Delta \mathrm{H}^{\circ}, \mathrm{kJ} / \mathrm{mol}\right)$ using different theoretical schemes.

\begin{tabular}{|c|c|c|c|c|}
\hline & \multicolumn{4}{|c|}{$\Delta \mathrm{H}^{\circ}$} \\
\hline Method & $\mathrm{H}_{2} \mathrm{O}$ & $\mathrm{NH}_{3}$ & $\mathrm{CH}_{3} \mathrm{OH}$ & $\mathrm{CH}_{3} \mathrm{NH}_{2}$ \\
\hline QCISD(T)/Stutt & -103.9 & -145.0 & -123.2 & -158.7 \\
\hline QCISD(T)/Stutt_3df & -105.0 & -145.4 & -124.6 & -159.8 \\
\hline QCISD(T)/SKBJ & -144.2 & -181.2 & -168.8 & -203.9 \\
\hline QCISD(T)/SKBJ_3df & -140.1 & -176.4 & -165.1 & -199.7 \\
\hline $\operatorname{CCSD}(\mathrm{T}) /$ Stutt & -103.1 & -144.9 & -123.4 & -158.6 \\
\hline CCSD(T)/Stutt_3df & -105.0 & -145.4 & -124.4 & -159.7 \\
\hline CCSD(T)/SKBJ & -144.1 & -181.1 & -168.6 & -203.9 \\
\hline CCSD(T)/SKBJ_3dfa & -145.1 & -181.6 & -169.9 & -204.8 \\
\hline B3LYP/Stutt & -107.7 & -143.6 & -125.9 & -157.4 \\
\hline B3LYP/Stutt_3df ${ }^{a}$ & -107.2 & -143.3 & -126.0 & -158.3 \\
\hline B3LYP/SKBJ & -149.3 & -181.6 & -171.9 & -200.6 \\
\hline B3LYP/SKBJ_3df ${ }^{a}$ & -149.1 & -181.6 & -172.1 & -201.2 \\
\hline G96LYP/Stutt & -99.7 & -139.2 & -118.4 & -153.9 \\
\hline G96LYP/Stutt_3df ${ }^{a}$ & -99.8 & -139.4 & -119.0 & -152.9 \\
\hline G96LYP/SKBJ & -141.0 & -176.6 & -164.1 & -197.3 \\
\hline G96LYP/SKBJ_3df & -140.6 & -176.5 & -164.3 & -197.8 \\
\hline Experimental & -93.7 & -118.4 & -97.5 & -148.1 \\
\hline
\end{tabular}

${ }^{\text {a }}$ Calculations carried out using a 6-311+G(3df,2p) basis set expansion 
Table 5. Effect of the optimized geometry on the calculated $\mathrm{Pb}^{+}$binding enthalpies $\left(\Delta \mathrm{H}^{\circ}, \mathrm{kJ} \mathrm{mol}^{-1}\right)$ obtained through the use of different ab initio schemes.

\begin{tabular}{|c|c|c|c|c|}
\hline & \multicolumn{4}{|c|}{$\Delta \mathrm{H}^{\circ}$} \\
\hline Method & $\mathrm{H}_{2} \mathrm{O}$ & $\mathrm{NH}_{3}$ & $\mathrm{CH}_{3} \mathrm{OH}$ & $\mathrm{CH}_{3} \mathrm{NH}_{2}$ \\
\hline MP2/Stutt & -104.9 & -145.4 & -125.2 & -160.5 \\
\hline MP2/SKBJ & -133.1 & -169.7 & -158.2 & -193.2 \\
\hline QCISD(T)/Stutt & -103.9 & -145.0 & -123.2 & -158.7 \\
\hline QCISD(T)/Stutt(B3LYP) ${ }^{\mathrm{a}}$ & -100.3 & -140.0 & -122.5 & -156.8 \\
\hline QCISD(T)/Stutt(G96LYP) ${ }^{\mathrm{b}}$ & -103.1 & -140.2 & -122.5 & -157.4 \\
\hline QCISD(T)/SKBJ & -144.2 & -181.2 & -168.8 & -203.9 \\
\hline QCISD(T)/SKBJ(B3LYP) ${ }^{a}$ & -140.9 & -177.1 & -168.3 & -199.5 \\
\hline QCISD(T)/SKBJ(G96LYP) & -143.8 & -177.9 & -168.2 & -202.5 \\
\hline CCSD(T)/Stutt & -103.1 & -144.9 & -123.0 & -158.6 \\
\hline CCSD(T)/Stutt(B3LYP) ${ }^{a}$ & -100.3 & -139.9 & -122.3 & -156.7 \\
\hline CCSD(T)/Stutt(G96LYP) & -103.1 & -140.2 & -122.3 & -157.3 \\
\hline $\operatorname{CCSD}(\mathrm{T}) / \mathrm{SKBJ}$ & -144.1 & $-181,1$ & -168.6 & -203.9 \\
\hline CCSD(T)/Stutt(B3LYP) ${ }^{a}$ & -140.9 & -177.0 & -168.1 & -200.0 \\
\hline CCSD(T)/Stutt(G96LYP) & -143.7 & -177.9 & -168.0 & -202.4 \\
\hline Experimental & -93.7 & -118.41 & -97.5 & -148.11 \\
\hline
\end{tabular}

${ }^{\text {a }}$ Calculations based on B3LYP/6-31G(d,p) optimized geometries

${ }^{\mathrm{b}}$ Calculations based on G96LYP/6-31G(d,p) optimized geometries 

Table 6. $\mathrm{Pb}^{+}$binding enthalpies $\left(\Delta \mathrm{H}^{\circ}, \mathrm{kJ} \mathrm{mol}^{-1}\right)$ calculated using different functionals.

\begin{tabular}{|c|c|c|c|c|}
\hline & \multicolumn{5}{|c|}{$\Delta \mathrm{H}^{\circ}$} \\
\hline Method & $\mathrm{H}_{2} \mathrm{O}$ & $\mathrm{NH}_{3}$ & $\mathrm{CH}_{3} \mathrm{OH}$ & $\mathrm{CH}_{3} \mathrm{NH}_{2}$ \\
\hline B3LYP/Stutt & -107.7 & -143.6 & -125.9 & -157.4 \\
\hline B3LYP/SKBJ & -149.3 & -181.6 & -171.9 & -200.6 \\
\hline B3PW91/Stutt & -112.9 & -153.2 & -129.8 & -167.4 \\
\hline B3PW91/SKBJ & -152.3 & -188.5 & -173.7 & -212.2 \\
\hline G96LYP/Stutt & -99.7 & -139.2 & -118.4 & -153.9 \\
\hline G96LYP/SKBJ & -141.0 & -176.6 & -164.1 & -197.3 \\
\hline MPW1PW91/Stutt & -113.1 & -153.0 & -129.8 & -166.1 \\
\hline MPW1PW91/SKBJ & -155.4 & -192.3 & -176.8 & -215.2 \\
\hline PBEPBE/Stutt & -118.0 & -160.6 & -136.5 & -175.7 \\
\hline PBEPBE/SKBJ & -160.2 & -198.8 & -183.7 & -224.9 \\
\hline PBE1PBE/Stutt & -115.4 & -155.5 & -131.8 & -168.1 \\
\hline PBE1PBE/SKBJ & -157.7 & -193.3 & -178.8 & -217.8 \\
\hline BLYP/Stutt & -106.2 & -143.9 & -126.2 & -158.3 \\
\hline BLYP/SKBJ & -147.3 & -181.1 & -171.7 & -203.4 \\
\hline ExPerimental & -93.7 & -118.4 & -97.5 & -148.1 \\
\hline
\end{tabular}

